\title{
Article
}

\section{Studying the Thermally Activated Processes Operating during Deformation of hcp and bcc Mg-Li Metal-Matrix Composites}

\author{
Zuzanka Trojanová $^{1}\left(\mathbb{D}\right.$, Zdeněk Drozd $^{1, *} \mathbb{B}$, Pavel Lukáč ${ }^{1}$ and Ján Džugan ${ }^{2}$ (D) \\ 1 Faculty of Mathematics and Physics, Charles University, Ke Karlovu 3, 12116 Prague, Czech Republic; \\ ztrojan@met.mff.cuni.cz (Z.T.); lukac@met.mff.cuni.cz (P.L.) \\ 2 Comtes FHT, Průmyslová 996, 33441 Dobřany, Czech Republic; jdzugan@comtesfht.cz \\ * Correspondence: zdenek.drozd@mff.cuni.cz
}

Citation: Trojanová, Z.; Drozd, Z.; Lukáč, P.; Džugan, J. Studying the Thermally Activated Processes Operating during Deformation of hcp and bcc Mg-Li Metal-Matrix Composites. Metals 2021, 11, 473. https://doi.org/10.3390/met11030473

Academic Editor:

Alexander Vorozhtsov

Received: 29 January 2021

Accepted: 11 March 2021

Published: 13 March 2021

Publisher's Note: MDPI stays neutral with regard to jurisdictional claims in published maps and institutional affiliations.

Copyright: (c) 2021 by the authors. Licensee MDPI, Basel, Switzerland. This article is an open access article distributed under the terms and conditions of the Creative Commons Attribution (CC BY) license (https:// creativecommons.org/licenses/by/ $4.0 /)$.

\begin{abstract}
Stress-relaxation tests were performed during plastic deformation at room temperature of three magnesium $\mathrm{Mg}-\mathrm{Li}$ alloys reinforced with 10 vol\% of short Saffil fibers. For comparison, the composite with the $\mathrm{Mg}$ matrix was studied. The time dependencies of the stress decrease were analyzed with the aim to determine the activation volume and the main types of thermally activated processes occurring during plastic flow. The Mg4Li matrix alloy exhibited the hcp structure, while the composite with the Mg12Li matrix alloy had the bcc structure. The third alloy, Mg8Li, combined both phases, hcp and bcc. The stress acting in the matrix was divided into two components: the internal stress and the effective stress. Activation volume and stress-sensitivity parameters were determined as a function of effective stress and strain. While the values of the activation volume depending on the effective stress lay on one "master" curve, the strain dependence was different for all materials. The main thermally activated process in the hcp structure was the dislocation motion in the noncompact planes, while in the bcc structure, massive recovery processes connected with an increase in dislocations were identified.
\end{abstract}

Keywords: magnesium alloy; short-fiber composite; internal stress; stress-relaxation test; thermally activation processes

\section{Introduction}

In the stress-relaxation (SR) test, the samples are deformed up to a certain stress, $\sigma(0)$, then the testing machine is abruptly stopped and the subsequent decrease in stress, $\sigma$, is recorded depending on time, $t[1-4]$. Successive SR tests may be used to study different aspects of plastic deformation [5-8].

The strain rate of plastic flow, $\dot{\varepsilon}$, controlled by thermal fluctuations can be written as:

$$
\dot{\varepsilon}=\dot{\varepsilon}_{0} \exp \left(-\frac{G^{*}\left(\sigma^{*}\right)}{K T}\right)
$$

where $\dot{\varepsilon}$ is the strain rate; $\dot{\varepsilon}_{0}$ is a model constant depending on the dislocation density, vibration frequency, and the area swept by a dislocation segment after the successful activation; and $G^{*}$ is the Gibbs free energy of activation, which depends on the effective stress, $\sigma^{*}$, necessary to overcome local obstacles for dislocation motion:

$$
\sigma^{*}=\sigma_{\mathrm{a}}-\sigma_{\mathrm{i}}
$$

and $k T$ has its usual meaning. In Equation (2), $\sigma_{\mathrm{a}}$ is applied stress and $\sigma_{\mathrm{i}}$ is a long-range internal stress arising from the elastic stress field of other dislocations. The internal stress aids the slip of dislocations. The Gibbs free energy $G^{*}$ is determined by the rate equation:

$$
G^{*}\left(\sigma^{*}\right)=-k T \ln \left(\frac{\dot{\varepsilon}}{\dot{\varepsilon}_{0}}\right)
$$


In general thermodynamics, the activation volume $V$ is defined as the negative stress derivative of the activation energy at a given temperature $T$ :

$$
V=-\left(\frac{\partial G^{*}}{\partial \sigma^{*}}\right)=k T\left(\frac{\partial \ln \left(\frac{\dot{\varepsilon}}{\dot{\varepsilon}_{0}}\right)}{\partial \sigma^{*}}\right)
$$

An alternative approach follows from the direct observation of dislocation. According to the dislocation dynamics, the mean dislocation velocity, $v$ :

$$
v=v_{0}\left(\frac{\sigma^{*}}{\sigma_{0}^{*}}\right)^{m^{*}}
$$

where $v_{0}$ and $\sigma_{0}^{*}$ are parameters. Considering the Taylor equation:

$$
\dot{\varepsilon}=\rho_{m} b v
$$

it is possible to write:

$$
\dot{\varepsilon}=B\left(\sigma^{*}\right)^{m^{*}}
$$

The stress-sensitivity parameter, $n^{*}$, may be calculated as:

$$
n^{*}=\frac{\partial \ln \dot{\varepsilon}}{\partial \ln \sigma^{*}}=\sigma^{*}\left(\partial \ln \dot{\varepsilon} / \partial \sigma^{*}\right)
$$

and the activation volume, $V$ as:

$$
V=\frac{k T n^{*}}{\sigma^{*}}
$$

Magnesium-lithium alloys are attractive materials for applications in which weight must be reduced. Magnesium-lithium alloys may have reduced density down to $1.35 \times 10^{3} \mathrm{kgm}^{-3}$ and remain acceptable with a high specific strength and good formability. A solid solution of $\mathrm{Li}$ in $\mathrm{Mg}$ retains a hexagonal close-packed structure (hcp) up to $5.6 \mathrm{wt} \%$ of $\mathrm{Li}$. This $\alpha$ hcp phase shows moderate strength and low ductility. The ductility increases with larger addition of $\mathrm{Li}$, achieving the $\mathrm{Li}$ content of $10.8 \mathrm{wt} \%$, and the structure changes to bodycentered cubic (bcc) $\beta$ phase. The strength of the $\beta$ phase is lower compared to the hcp $\alpha$ phase. Further disadvantages of alloys with higher Li content are significant chemical activity and low corrosion resistance. Alloys containing between 5.6 and $10.8 \mathrm{wt} \%$ of Li are a compromise with good ductility and acceptable strength. The mechanical properties of $\mathrm{Mg}-\mathrm{Li}$ alloys were studied in several papers [9-12]. Metal-matrix composites (MMC) based on $\mathrm{Mg}-\mathrm{Li}$ alloys possess many advanced properties: increased strength and creep resistance, improved high temperature properties, increased wear resistance, and increased dimension stability because of decreased thermal expansion [13-15].

High-temperature sensitivity of deformation stresses observed in Mg-Li MMCs [15] indicates the presence of thermally activated processes. The stress-relaxation test is an effective method with which to investigate the thermally activated processes during deformation, especially dislocation processes. In our study, the thermally activated flow of dislocations was studied in three $\mathrm{Mg}-\mathrm{Li}$ MMCs with the aim to find the parameters of the thermally activated processes and reveal their principles. These processes should be different in hcp and bcc phases. Four MMCs were examined: $\mathrm{Mg}, \mathrm{Mg} 4 \mathrm{Li}, \mathrm{Mg} 8 \mathrm{Li}$, and $\mathrm{Mg} 12 \mathrm{Li}$, all reinforced with $10 \mathrm{vol} \%$ of short Saffil fibers.

\section{Materials and Methods}

$\mathrm{Mg}$ and $\mathrm{Mg}-\mathrm{Li}$ composites reinforced with short $\delta$-alumina fibers were manufactured by the pressure-infiltration process. The preform consisting of short commercial Saffil fibers $\left(96 \% \mathrm{Al}_{2} \mathrm{O}_{3}, 4 \% \mathrm{SiO}_{2}\right)$ was manufactured via water dispersion, sedimentation, and drying. The preform was prepared without any binder. The preform was then put into a steel 
container and evacuated up to $10 \mathrm{~Pa}$. The preform was infiltrated by the melt preheated to $690^{\circ} \mathrm{C}$ under a pressure of $6 \mathrm{MPa}$ for $30 \mathrm{~s}$. The process occurred under a protective $\mathrm{Ar}$ atmosphere. The structure of the composite materials consisted of short $\delta-\mathrm{Al}_{2} \mathrm{O}_{3}$ fibers (10 vol\%) distributed planar-randomly within the $\mathrm{Mg}-\mathrm{Li}$ matrix. No significant fiber damage resulting from the $\mathrm{Mg}-\mathrm{Li}$ melt attack was observed. Microstructure of the samples was revealed after grinding, polishing, and etching for $30 \mathrm{~s}$ in a $1 \%$ solution of the NITAL etching agent. Microphotos were taken with an Olympus light microscope. Cylindrical samples with a diameter of $5 \mathrm{~mm}$ and height of $7 \mathrm{~mm}$ were deformed in compression at room temperature in an INSTRON 1186 deformation machine with the initial strain rate $\dot{\varepsilon}=2.4 \times 10^{-4} \mathrm{~s}^{-1}$.

In the SR test, $\dot{\varepsilon}=-\dot{\sigma} / M$, where $\mathrm{M}$ is a complex modulus of the sample and deformation machine, which may be constant during the SR test. Thus, the SR experiments are one of methods how to obtain the stress sensitivity parameter, $\left(\partial \ln \left(\frac{\dot{\varepsilon}}{\dot{\varepsilon}_{0}}\right) / \partial \sigma^{*}\right) T$, and the activation volume, $V$.

The duration of each SR test was $300 \mathrm{~s}$. Subsequently, $4-5$ of the SR tests along the stress-strain curve were performed. A schematic of the SR test is shown in Figure 1. In MMCs, a significant portion of the applied stress is carried by the reinforcing phase fibers [15-18]. The Young's modulus of Saffil fibers is about $300 \mathrm{GPa}$ and the yield strength is $1.5 \mathrm{GPa}$, i.e., during plastic deformation, the Saffil fibers are deformed elastically while the matrix is plastically strained. The load transfer from the metallic matrix to fibers may be calculated based on the shear lag model [16,18]:

$$
\sigma_{\mathrm{c}}=\sigma_{\mathrm{m}}(1+(L+d) A / 4 L) f+\sigma_{\mathrm{m}}(1-f)
$$

where $\sigma_{\mathrm{c}}$ is the stress necessary for composite deformation if only load transfer is taken into account, $\sigma_{\mathrm{m}}$ is stress in the matrix, $f$ is volume fraction of the reinforcing phase, and $L$ and $d$ are the fiber length and diameter, respectively. $A$ is the fiber aspect ratio, $A=L / d$. The stress in the matrix, $\sigma_{\mathrm{m}}$, was calculated using relationship (10). The stress contribution due to the load transfer $\Delta \sigma_{\mathrm{LT}}=\sigma_{\mathrm{c}}-\sigma_{\mathrm{m}}$ was calculated for the short fibers aligned with the stress direction. $\mathrm{Mg}-\mathrm{Li}$ composites exhibit only the fiber plane parallel to the stress direction, i.e., only a part of the load transfer $\beta . \Delta \sigma_{\mathrm{LT}}$, where $\beta=0.6$ is the mean value of the direction cosines. Components of the stress in the matrix $\left(\sigma_{\mathrm{mi}}, \sigma_{\mathrm{m}}{ }^{*}\right)$ were estimated using Li's method $[19,20]$. The SR curves were fitted to the power law function in the form:

$$
\sigma_{m}-\sigma_{m i}=[a(p-1)]^{\frac{1}{1-p}}\left(t+t_{0}\right)^{\frac{1}{1-p}}
$$

where $a, t_{0}$, and $\mathrm{p}$ are fitting parameters. The stress decrease with time during the SR test can be described by Equation (12) [1,2]:

$$
\Delta \sigma_{\mathrm{m}}(t)=\sigma_{\mathrm{m}}(0)-\sigma_{\mathrm{m}}(t)=\alpha \ln (\beta t+1)
$$

where $\sigma_{\mathrm{m}}(0) \equiv \sigma(0)$ is the stress at the beginning of the stress relaxation at time $t=0$, and

$$
\alpha=\frac{k T}{V}
$$

where $V$ is the activation volume. Equations (12) and (13) were used for the calculation of activation volume. 


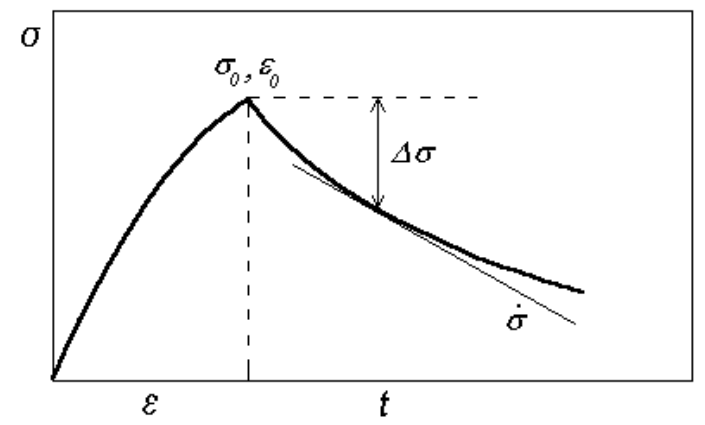

Figure 1. A schematic of the stress relaxation test.

\section{Results}

The microstructure of the Mg4Li composite with $\alpha$ hcp phase is shown in Figure $2 \mathrm{a}$. The grain size estimated by the standard metallographic method was $80 \mu \mathrm{m}$. The microstructure of the Mg12Li alloy exhibiting the bcc $\beta$ phase is reported in Figure 2c. The grain size of $75 \mu \mathrm{m}$ in this phase is close to the grain size of the $\alpha$ phase. The grain boundaries in the Mg8Li MMC with $(\alpha+\beta)$ phases (see Figure $2 b$ ) were not detected. They were very probably identical with the phase boundaries of lighter $\alpha$ and darker $\beta$ phase.

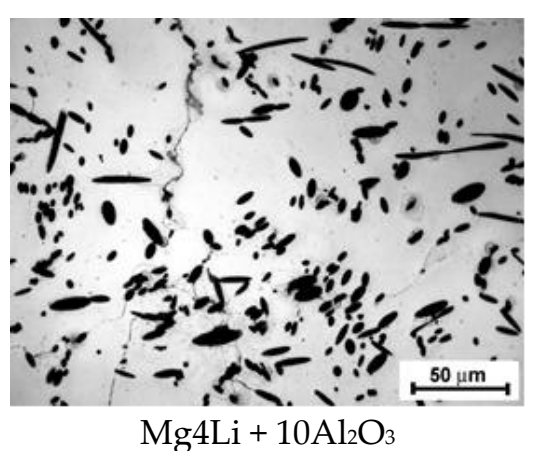

(a)

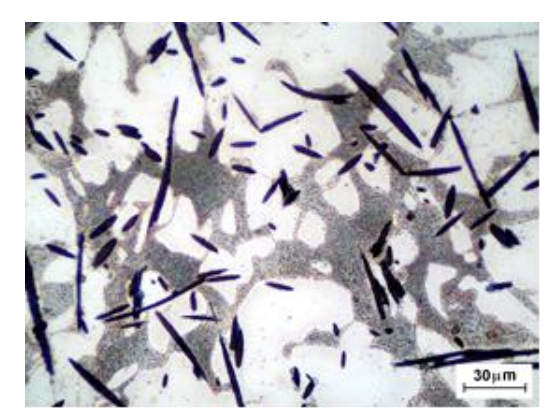

$\mathrm{Mg} 8 \mathrm{Li}+10 \mathrm{Al}_{2} \mathrm{O}_{3}$

(b)

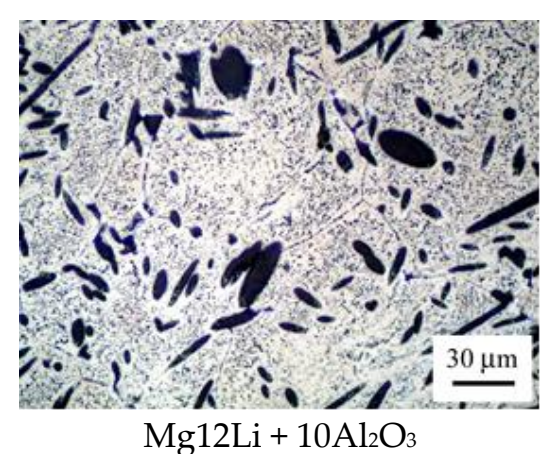

(c)

Figure 2. Microstructure of composites: (a) $\mathrm{Mg} 4 \mathrm{Li}+10 \mathrm{Al}_{2} \mathrm{O}_{3} ;\left(\right.$ b) $\mathrm{Mg} 8 \mathrm{Li}+10 \mathrm{Al}_{2} \mathrm{O}_{3} ;(\mathbf{c}) \mathrm{Mg} 12 \mathrm{Li}+10 \mathrm{Al}_{2} \mathrm{O}_{3}$.

The compressive stress-strain curves with cut SR curves are shown in Figure 3 for pure $\mathrm{Mg}$ and three $\mathrm{Mg}-\mathrm{Li}$ alloys reinforced with Saffil fibers. It can be seen that in the case of the Mg, Mg8Li, and Mg12Li MMCs, each subsequent active deformation after the SR test started at the same stress. The upper yield stress after the stress relaxation observed in the Mg4Li composite was caused by dynamic strain ageing during the SR test. 


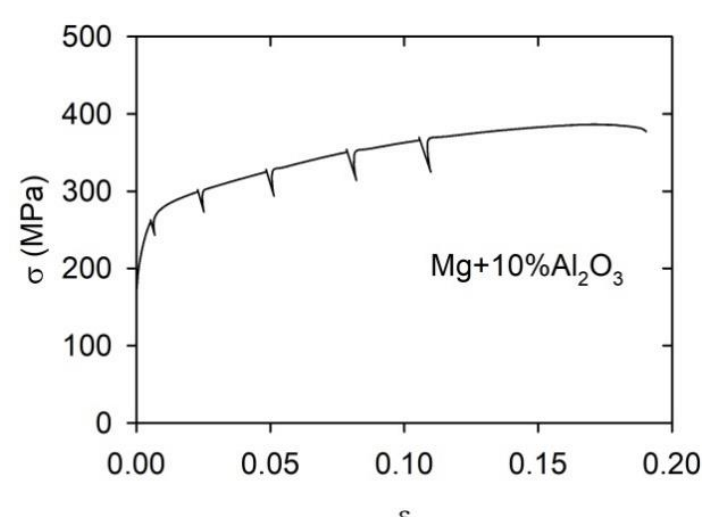

(a)

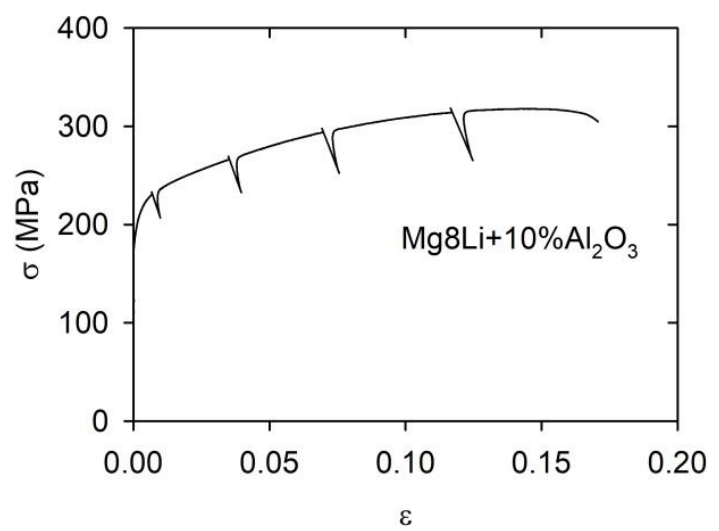

(c)

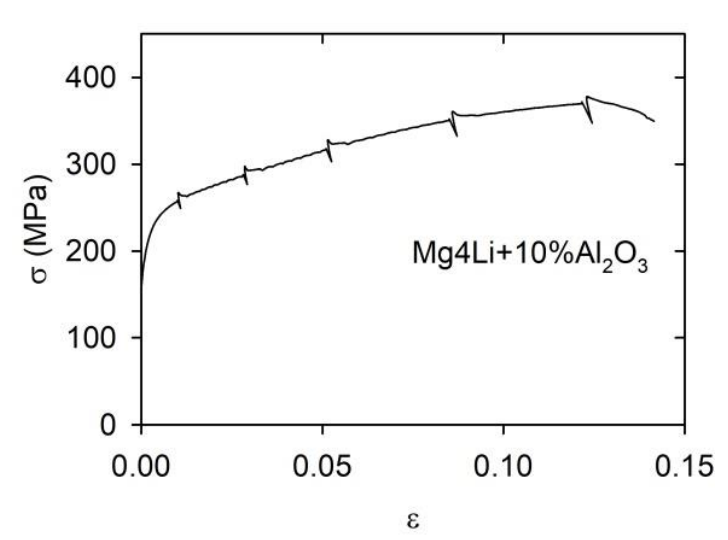

(b)

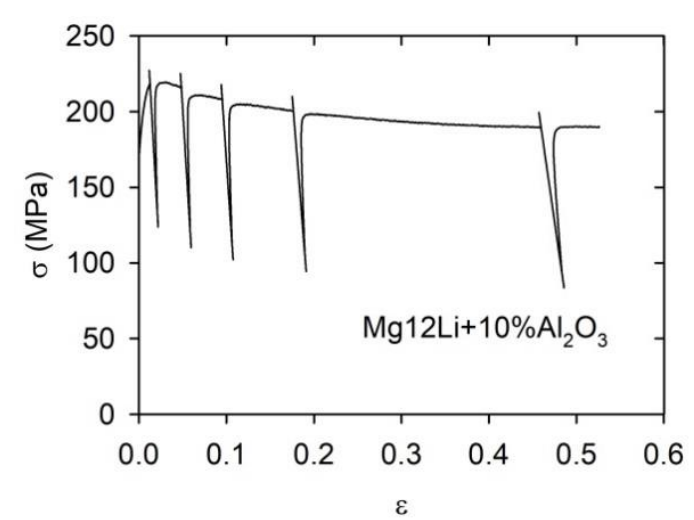

(d)

Figure 3. Stress-strain curves where stress-relaxation curves were cut: (a) Mg, (b) Mg4Li, (c) Mg8Li, and (d) Mg12Li.

The series of SR curves normalized to the starting stress $\sigma(0)$ are shown in Figure 4a-d. While the minimum stress decrease observed in the Mg4Li composite was only several percent, in the Mg12Li composite, the stress decrease achieved was $~ 50 \%$.

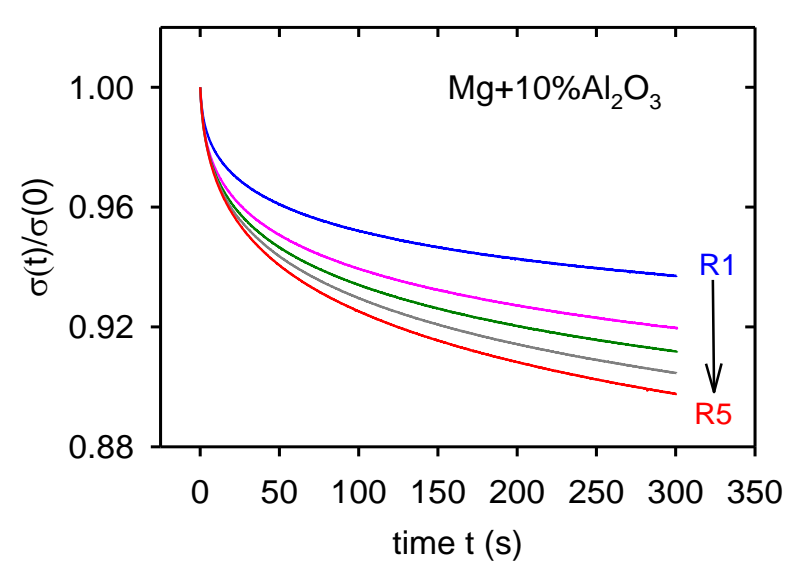

(a)

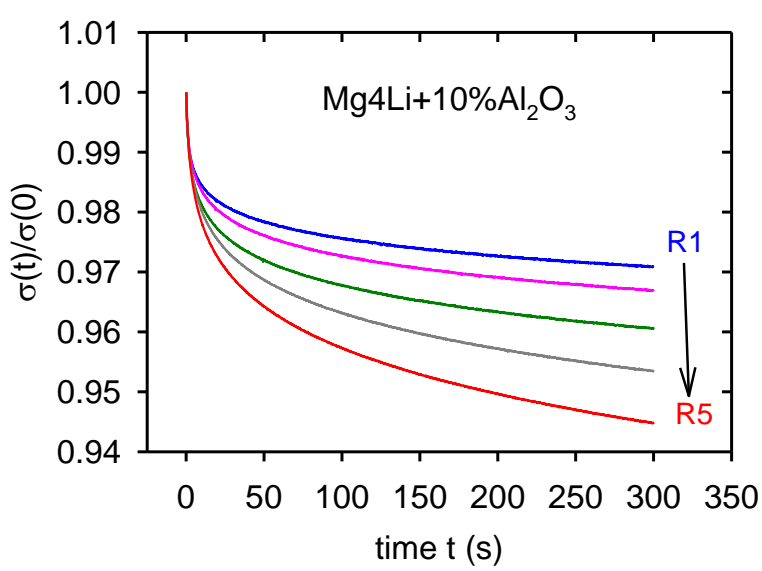

(b)

Figure 4. Cont. 


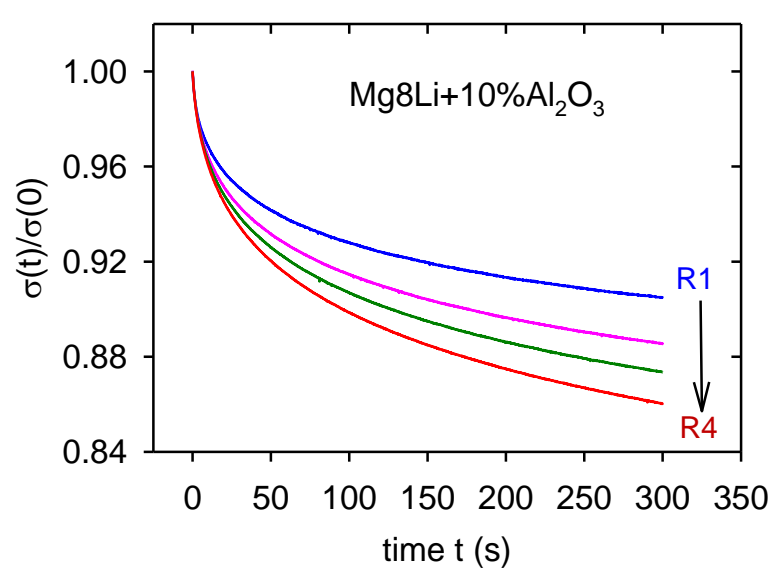

(c)

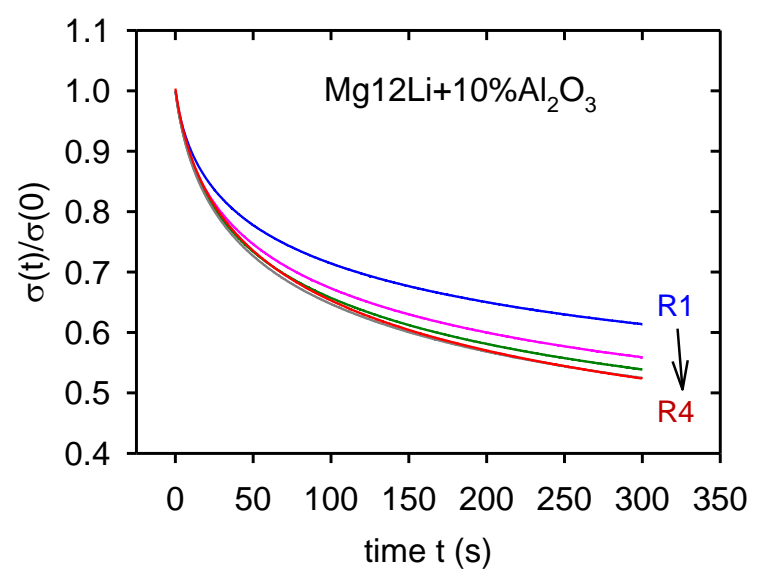

(d)

Figure 4. The sequences of stress-relaxation curves obtained for (a) $\mathrm{Mg}$, (b) $\mathrm{Mg} 4 \mathrm{Li}$, (c) $\mathrm{Mg} 8 \mathrm{Li}$, and (d) $\mathrm{Mg} 12 \mathrm{Li}$ alloys with 10 vol\% Saffil fibers.

Parts of the stress-strain curves together with the calculated strain dependencies of the stress in the matrix, $\sigma_{\mathrm{m}}$, are shown in Figure $5 \mathrm{a}-\mathrm{d}$, with the indicated points in which the SR tests were performed. This matrix stress was divided into two components: the internal stress in the matrix, $\sigma_{\mathrm{mi}}$, and thermal stress component, $\sigma_{\mathrm{m}}{ }^{*}$. MMCs with $\mathrm{Mg}$, $\mathrm{Mg} 4 \mathrm{Li}$, and Mg8Li exhibited a high level of internal stress in the matrix. The internal stress in the Mg12Li matrix was very low-lower than the effective stress in the matrix, $\sigma_{\mathrm{m}}{ }^{*}$.

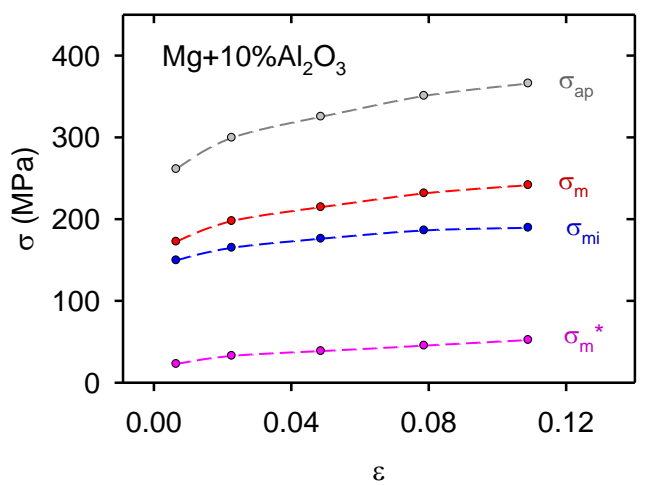

(a)

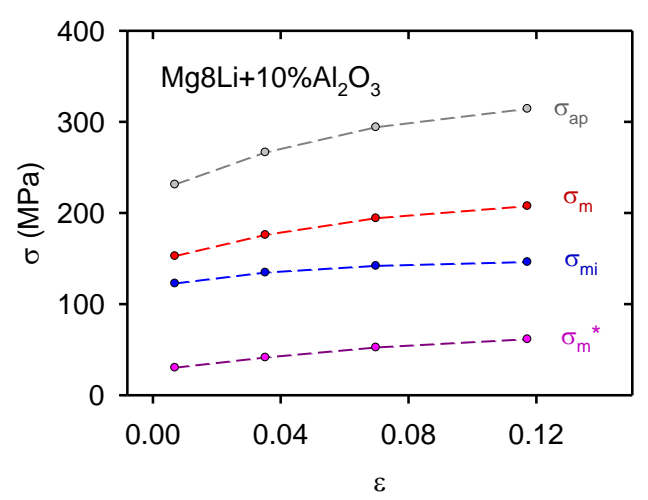

(c)

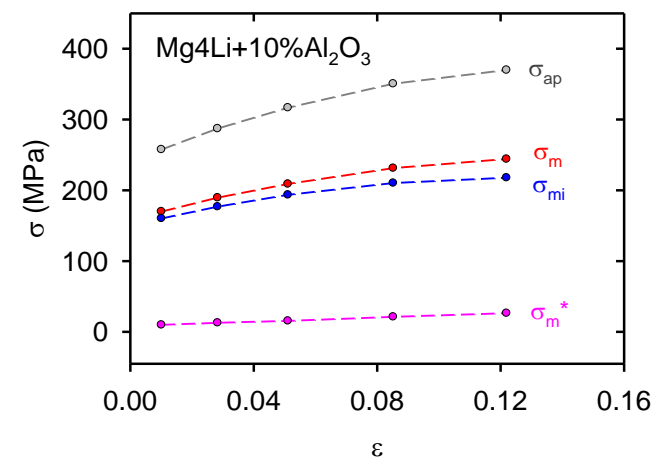

(b)

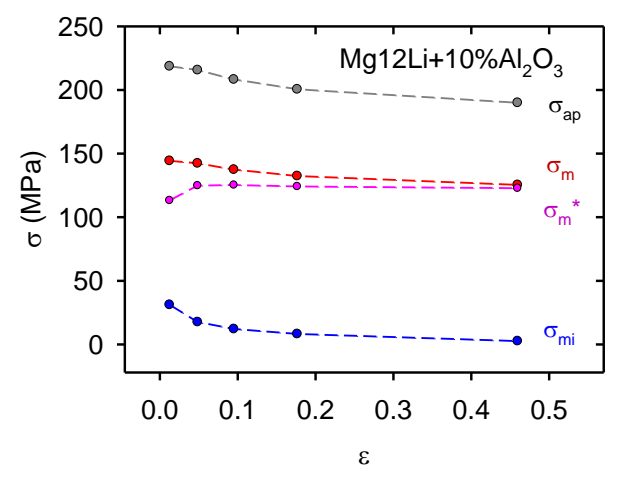

(d)

Figure 5. Strain dependences of the applied stress, $\sigma_{\text {ap }}$; matrix stress, $\sigma_{\mathrm{m}}$; internal stress in the matrix, $\sigma_{\mathrm{mi}}$; and the effective stress in the matrix, $\sigma_{\mathrm{m}}{ }^{*}$. The indicated points depict the SR tests. (a) $\mathrm{Mg}+10 \% \mathrm{Al}_{2} \mathrm{O}_{3},(\mathbf{b}) \mathrm{Mg} 4 \mathrm{Li}+10 \% \mathrm{Al}_{2} \mathrm{O}_{3},(\mathbf{c}) \mathrm{Mg} 8 \mathrm{Li}+$ $10 \% \mathrm{Al}_{2} \mathrm{O}_{3}$, (d) $\mathrm{Mg} 12 \mathrm{Li}+10 \% \mathrm{Al}_{2} \mathrm{O}_{3}$ 


\section{Discussion}

The activation volumes, $V$, estimated for all materials were plotted against the effective stress in the matrix, $\sigma_{\mathrm{m}}{ }^{*}$, in the linear and bilogarithmic scale (Figure $6 \mathrm{a}, \mathrm{b}$ ). As shown in Figure $6 \mathrm{a}, \mathrm{b}$, the experimental values of $V$ followed a dependence that can be expressed as $V \sim\left(\sigma_{\mathrm{m}}^{*}\right)^{-n}$ where the stress exponent $n=1.2$. The strain rate sensitivity $n^{*}=1 / \mathrm{m}^{*}$ (where $\mathrm{m}^{*}$ is the stress rate sensitivity) parameters calculated from Equation (9), for all composites depending on the effective stress, are reported in Figure 6c. Values of the strain rate sensitivity parameters can be aligned into three linear dependencies for composites based on Mg4Li, Mg and Mg8Li, and Mg12Li. Kocks et al. [21] have published the stress dependence of the Gibbs enthalpy:

$$
\Delta G=\Delta G_{0}\left[1-\left(\frac{\sigma^{*}}{\sigma_{0}^{*}}\right)^{p}\right]^{q}
$$

where $p$ and $q$ are phenomenological parameters limited by the conditions, $0<p \leq 1$ and $1 \leq q \leq 2$. Specific values of $p$ and $q$ depend on the obstacle shape and resistance profile. The strain rate can be expressed as:

$$
\dot{\varepsilon}=\dot{\varepsilon}_{0} \exp \left[-\frac{\Delta G_{0}}{k T}\left(1-\left(\frac{\sigma^{*}}{\sigma_{0}^{*}}\right)^{p}\right)^{q}\right]
$$

and therefore, the activation volume, $\mathrm{V}$, by the following relationship:

$$
V=k T \frac{\partial \ln \varepsilon / \dot{\varepsilon}_{0}}{\partial \sigma^{*}}=\frac{\Delta G_{0} p q}{\sigma_{0}^{*}}\left[1-\left(\frac{\sigma^{*}}{\sigma_{0}^{*}}\right)^{p}\right]^{q-1}\left(\frac{\sigma^{*}}{\sigma_{0}^{*}}\right)^{p-1}
$$

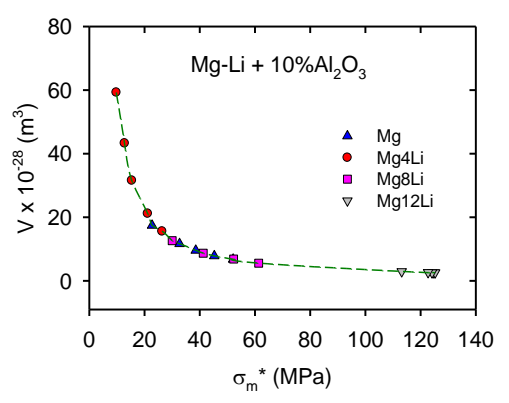

(a)

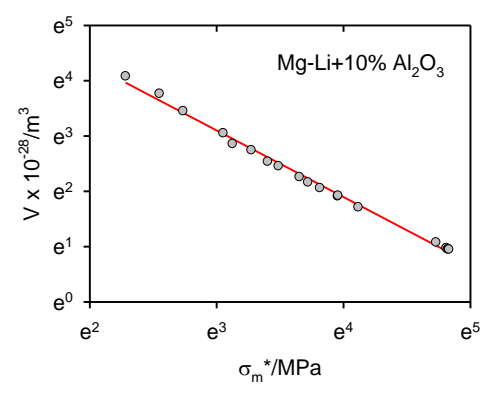

(b)

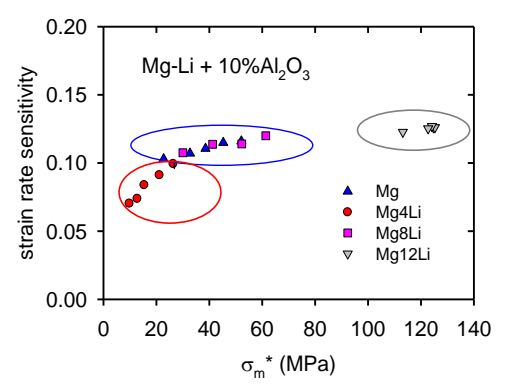

(c)

Figure 6. Activation volume depending on the effective stress in the matrix (a) in linear scale, (b) in bilogarithmic scale, (c) strain rate sensitivity depending on the effective stress in the matrix. Values estimated for all materials.

Equation (16) describes the experimental curve shown in Figure 6a,b. Using the binominal expansion in Equation (16), the activation volume, V, should depend on the effective stress as $V \propto\left(\sigma^{*}\right)^{-n}$. As it follows from Figure $6 \mathrm{~b}$, this dependence was fulfilled very well. While values of the activation volume, dependent on the effective stress, lay on one "master curve", different dependences of the strain rate sensitivity on the effective stress in the matrix were estimated for various materials (see Figure $6 \mathrm{c}$ ). This finding indicates different mechanisms operating in the individual composites.

\section{1. $\mathrm{Mg}$ and Mg4Li Composites ( $\alpha$ Phase)}

Both composites exhibited hcp structure with the main slip system of $<a>=\frac{1}{3} 11 \overline{2} 0$ dislocations in basal (0001) plane. The $<a>$ dislocations were movable also in the $\{10 \overline{10}\}$ prismatic and $\{11 \overline{2} 1\}$ pyramidal planes. The activity of $<c+a>11 \overline{2} 3$ dislocations in the $\{11 \overline{2} 2\}$ pyramidal planes of the second order was necessary for deformation compatibility in polycrystals. Because the pyramidal and prismatic planes were not closely packed, they 
were called noncompact planes, as in the literature. However, the critical resolved shear stress (CRSS) in the nonbasal slip systems was much higher at room temperature compared to the CRSS in the basal system, as mechanical twinning accommodates deformation at lower temperatures. The commonly observed twinning modes are $\{10 \overline{1} 2\} \overline{1} 011$ extension twins and $\{10 \overline{1} 1\} 10 \overline{1} 2$ contraction twins [22,23].

The internal stress in the matrix $\sigma_{\mathrm{mi}}$ resulting from long-range internal stresses impeding the plastic flow is done by the known Taylor relationship [24]:

$$
\sigma_{i m}=\alpha_{1} M G b \varrho_{t}^{1 / 2}
$$

where $G$ is the shear modulus, $\alpha_{1}$ is a constant describing the interaction between dislocations, $M$ is the Taylor factor, $b$ is the magnitude of the Burgers vector of dislocations, and $\varrho_{t}$ is the total dislocation density.

Dislocation densities calculated according to Equation (17) taking for $\alpha_{1}=0.35$ [25], $M=4.5$ [26], shear modulus $G=17 \mathrm{GPa}$ and $b=3.2 \times 10^{-10} \mathrm{~m}$ were plotted against strain in Figure 7a. When density, $\varrho_{t}$, increases with increasing strain in the region of higher strain, a saturation may be observed.

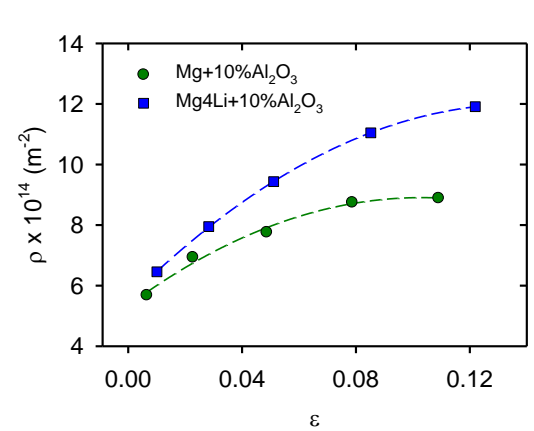

(a)

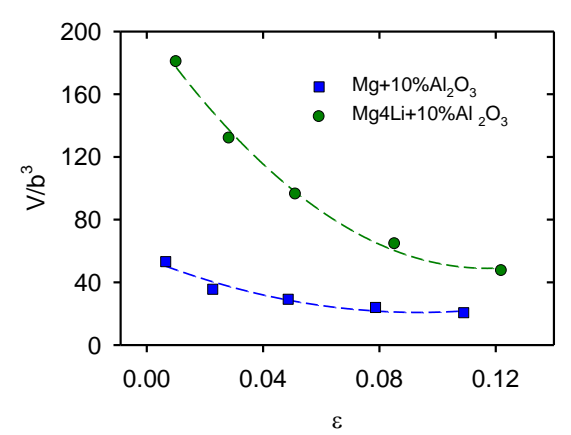

(b)

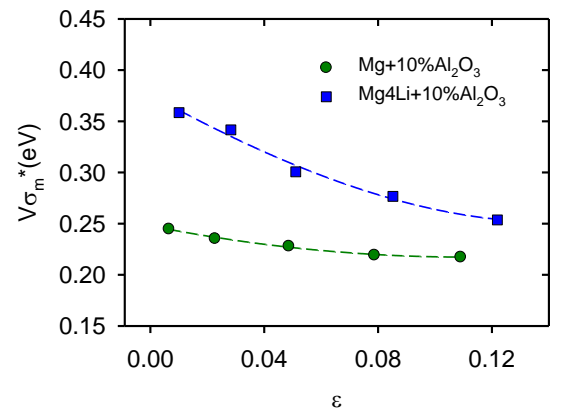

(c)

Figure 7. Calculated dislocation density, $\rho(\mathbf{a})$; activation volume, $V / b^{3}(\mathbf{b})$; and $V \sigma_{m}^{*}$ product (c) vs. strain $\varepsilon$ estimated for the $\mathrm{Mg}$ and $\mathrm{Mg} 4 \mathrm{Li}$ composites.

The total dislocation density $\varrho_{t}$ in MMCs is higher compared to metallic materials due to two reasons: (a) generation of thermal dislocations, and (b) the presence of dislocations that are geometrically necessary. Typically, the coefficient of thermal expansion (CTE) of the matrix is higher than the CTE of a ceramic reinforcement. When the MMC is cooled from a higher temperature to room temperature, misfit strains occur because of different thermal contractions at the matrix-reinforcement interface. These strains induce thermal stresses that may be higher than the yield stress of the matrix. The thermal stresses may be sufficient to generate new dislocations at the interfaces between the matrix and the reinforcements. Therefore, after cooling a composite, the dislocation density in the matrix increases. The density of newly created dislocation near reinforcement fibers can be calculated according to Arsenault and Shi [27]:

$$
\rho_{T}=\frac{B f \Delta \alpha \Delta T}{b(1-f)} \frac{1}{t_{m}}
$$

where $t_{m}$ is a minimum size of the reinforcing phase fibers, $B$ is a geometrical constant ( $B=10$ for fibers), and $\Delta \alpha \Delta T$ is the thermal strain ( $\Delta \alpha$ is the difference in the CTE and $\Delta T$ is the temperature change). When the thermal stresses achieve the yield stress, plastic zones can be formed in the matrix near the interfaces, especially near the fiber ends.

In addition, in the reinforcing phase, the geometrically necessary dislocations are generated to accommodate the mismatch of plastic deformation in the matrix. The density of the geometrically necessary dislocations may be expressed as [28]: 


$$
\rho_{G}=\frac{f 8 \varepsilon_{p}}{b t_{m}}
$$

where $\varepsilon_{\mathrm{p}}$ is the plastic strain. From relationship (19), it follows that the density of geometrically necessary dislocations increases with increasing strain. Introducing the reinforcing phases into the metal matrix influences not only the densities of the thermally formed and geometrically necessary dislocations, but also the dislocations stored at the reinforcements during deformation. Considering these effects, the total dislocation density in MMCs can be expressed as:

$$
\varrho_{\text {total }}=\varrho_{T}+\varrho_{G}+\left(\varrho_{S}+\varrho_{f}\right)
$$

where $\varrho_{S}$ is the statistically stored dislocation density on impenetrable obstacles in the unreinforced matrix, and $\varrho_{f}$ is the density of dislocations that are caught on the fibers. The effective spacing between impenetrable obstacles decreases. The mean spacing between the impenetrable obstacles, $s$, may be expressed as:

$$
1 / s=1 / d+1 / L_{t w}+1 / L_{f}+1 / L_{d p}+\cdots
$$

where $d$ is the grain size, $L_{\mathrm{tw}}$ is the distance between twins, and $L_{\mathrm{dp}}$ is the mean spacing between dislocation pile-ups. The mean free path of dislocations, $\Lambda$, is proportional to the spacing between dislocations $L_{d}=\varrho^{-1 / 2}$ :

$$
\Lambda=\varphi L_{d}=\varphi \varrho^{-1 / 2}
$$

where parameter, $\phi$, was found in [29] for a $\mathrm{Zr}-\mathrm{Sn}$ alloy to be $\phi=25$. Besides being impenetrable, the dislocation obstacles may be situated in the slip plane. These dislocation obstacles may arise in dislocation reactions [30].

The activation volumes, given as usual in units of $b^{3}$ and calculated according to Equation (13), are plotted in Figure $7 \mathrm{~b}$ depending on strain, $\varepsilon$. The activation volume values exhibited tens of $b^{3}$ for MMC with the Mg matrix, and for the Mg4Li composite, decreased with increasing strain from hundreds to tens of $b^{3}$. The main thermally activated process, active at room temperature and at higher temperatures, was found in previous papers to be the motion of dislocation by the Friedel-Escaig mechanism [31-34]. Dislocations are dissociated in basal (0001) planes. The partial dislocations are joined together along a critical length $L_{\mathrm{r}}$, and with the help of two kinks, transferred into nonbasal planes that may be prismatic or pyramidal planes of the first order. The activation volume is proportional to the critical length between two kinks. Amadieh et al. [35] analyzed this mechanism and found that the activation volume $V \sim 70 b^{3}$. Mathis et al. [36] studied the evolution of the dislocation density in deformed magnesium polycrystals by $\mathrm{X}$-ray diffraction. The authors of [36] found a majority of $<a>$ dislocations at the beginning of tensile deformation. During plastic deformation, the $<\mathrm{a}>$ dislocations remained dominant; however, the fraction of $<\mathrm{c}+\mathrm{a}>$ dislocations increased at the cost of $<\mathrm{a}>$ dislocations. Geometrical interpretation gives for the activation volume $V=b d \ell$, where $d$ is the local obstacle width and $\ell$ is the length of dislocation segments between obstacles. The critical length, $L_{\mathrm{r}}$, between two kinks may be considered as the length of the dislocation segments between local obstacles and the obstacle width, the dislocation dissociation connected with the stacking fault. With the increasing strain, the density, the length of dislocation segments between obstacles decreases, and then the activation volume.

The product $\sigma^{*} V=n^{*} k T$ depending on strain is shown in Figure 7c for both composites in units of eV. The product $\sigma^{*} V$ is the work of the stress in the matrix for the overcoming of local obstacles and represents a certain energetic measure of the thermally activated process during plastic deformation. The movement of dislocations with the solute atoms in their core was more energetically exacting compared to the $\mathrm{Mg}$ matrix. The stress sensitivity parameter $n^{*}$ may be written as:

$$
n^{*}=q \cdot \Delta G_{0} / \mathrm{kT}
$$


It is impossible to estimate the $q$ parameter from our experiments. This approach represents the energetic interpretation of the stress-sensitivity parameter, contrary to the geometrical interpretation of the activation volume.

In the Mg4Li MMC, the starting stress after the SR test was slightly higher compared with $\sigma_{0}$ at which the machine was stopped (see Figure 3b). A postrelaxation effect was observed in several magnesium alloys [37,38]. Such a phenomenon indicates the dynamic strain ageing during the SR test. The strain rate decreases during the SR test and the movable solute atoms may migrate to the moving dislocations and segregate in the elastic stress field of dislocation lines. The stress increment $\Delta \sigma$ after SR due to solute-atom segregation may be also expressed for a longer time, $t$, by the following equation $[39,40]$ :

$$
\Delta \sigma(\mathrm{t}, \varepsilon, \mathrm{T})=\Delta \sigma_{\mathrm{m}}(\varepsilon, \mathrm{T})\left\{1-\exp \left[-\left(\mathrm{t} / \mathrm{t}_{\mathrm{c}}\right)^{\mathrm{r}}\right]\right\}
$$

where $\Delta \sigma_{m}(\varepsilon, T)$ is the stress increment for time $t \rightarrow \infty$, and depends on the binding energy between solute atoms and dislocation; and $\mathrm{r}$ is a time exponent. It increases with increasing solute-atom concentration and with decreasing temperature. Characteristic time, $t_{c}$, depends on the strain as $t_{c} \sim \varepsilon^{-k}$, where $\mathrm{k}$ is a strain exponent [39]. Dlouhý et al. described the postrelaxation effect, $\Delta \sigma$, by a complex partial differential equation [41]. Solute atoms locking dislocations cause the stress increase after stress relaxation. An increase in the flow stress is needed to move the dislocations after stress relaxation. It is reasonable to assume that $\Delta \sigma$ is proportional to the concentration of solute atoms on the dislocation lines.

\subsection{Mg12Li ( $\beta$ Phase), Mg8Li $(\alpha+\beta)$ Phase}

Taylor and coworkers deformed single crystals of $\mathrm{Li}-\mathrm{Mg}$ alloys $(33-70 \%$ at $\% \mathrm{Mg}$ ) in tension and compression [42,43]. They measured the temperature dependence of the flow stresses and found that slip occurred at low temperatures in $<111>$ directions on $\{211\}$ planes. Saka and Taylor [44] interpreted these results in terms of the Peierls barrier. This mechanism is active up to approximately $200 \mathrm{~K}$. At higher temperatures, the thermally activated mechanism seems different. Exceptionally low values of the matrix internal stress in the bcc $\beta$ phase indicate a low dislocation density. Likewise, the values of the activation volume are very low, $\sim 10 \mathrm{~b}^{3}$ and practically independent on strain (see Figure $8 \mathrm{a}$ ). The Burgers vector in the bcc phase was taken as $b(\mathrm{Mg} 12 \mathrm{Li})=2.98 \times 10^{-10} \mathrm{~m}$ [45]. The $V \cdot \sigma^{*}$ product was almost constantly independent of strain, involving about $0.2 \mathrm{eV}$ (Figure $8 \mathrm{~b}$ ). These experimental results indicated that the deformation mechanism in the bcc phase was different from that operating in the hcp phase. The stress-strain curve exhibited a short region at the beginning of deformation (up to $\sim 2 \%$ ), and no work hardening. The deformation process had a steady-state character with a moderate stress decrease. Such behavior indicates that the work hardening and recovery processes were approximately in equilibrium. This situation is analogous to steady-state creep, where the strain rate is constant and further deformation occurs under a constant stress. Various models of the steady-state creep deformation may be found in the literature [46].

The stress decrease rate, $-\dot{\sigma}$, during the SR test was proportional to the strain rate $-\dot{\sigma} \sim \dot{\varepsilon}$ i.e., so Equation (7) is valid. In Figure 8c, the stress decrease rate $\lg (-\dot{\sigma})$ was plotted against $\lg (\sigma / \sigma(0))$ for the SR of the Mg12 Li composite with a starting matrix stress of $\sigma(0)=153.5 \mathrm{MPa}$. The dependence was linear with the slope of 6.88 , and with the correlation $c=0.998$. Similar slopes of $-\dot{\sigma} \sim \dot{\varepsilon}$ dependencies were found for other SR tests in Mg12Li composites, having values of 7.6-5.9, with a decreasing tendency for each subsequent SR test. Landau and Dotsenko [47] showed that the slope of the $\ln (-\dot{\sigma})$ vs. $\ln \dot{\sigma}$ dependence can be found analytically for dislocations moving in the twodimensional obstacle field. If the stationary creep is controlled by the dislocation glide, the activation enthalpy is close to the activation enthalpy of lattice diffusion and the creep rate is $\dot{\varepsilon} \sim \sigma^{4.5}$ [46]. The high values of the stress-sensitivity parameter estimated in the particular SR tests indicated that the process was controlled by the dislocation glide. The dislocation configurations were very probably not stable, and the dislocations annihilated 
in the recovery process. The decreasing SR starting stress indicated significant activity of the recovery process(es). The stress increase, observed when the deformation machine was stopped, was very probably due to low values of the internal stress in the matrix. Accumulated dislocations on alumina fibers move back from the fibers and cause the stress increase for a short time.

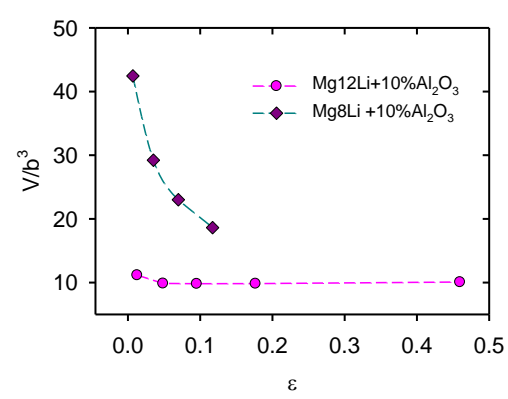

(a)

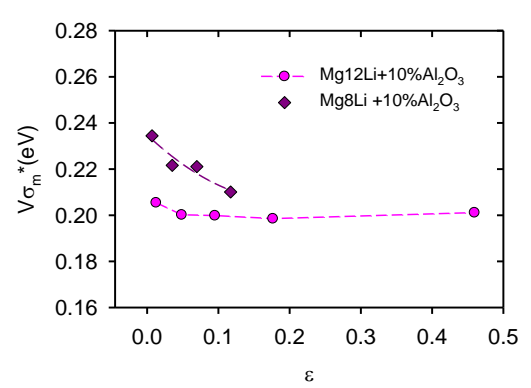

(b)

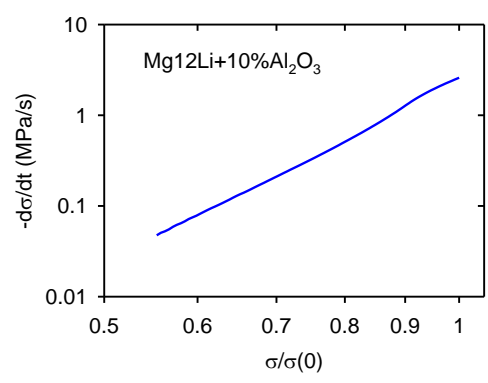

(c)

Figure 8. Activation volume $V / b^{3}(\mathbf{a})$, product $V \sigma_{m}^{*}(\mathbf{b})$ depending on strain. Stress decrease rate $-\dot{\sigma}$ vs. $\sigma / \sigma(0)$ is in the bilogarithmic scale (c).

Values of the activation volume found for the Mg8Li composite are shown in Figure 8a in the dimensionless $b^{3}$ representation. The activation volume decreased with increasing strain approximately twice. The values were lower than the values found in the Mg4Li matrix, but higher compared to the Mg12Li MMC. The $V \cdot \sigma_{m}^{*}$ energy decreased with strain, as shown in Figure $8 \mathrm{~b}$. A combination of both thermally activated processes may be found in the Mg8Li alloy. The deformation (and deformation during the SR test) were different in the $\alpha$ and $\beta$ phases. While in the $\alpha$ phase, significant hardening was observed, and massive recovery processes contributed to the higher ductility in the $\beta$ phase.

\section{Conclusions}

Magnesium and $\operatorname{Mg} x \operatorname{Li}$ alloys $(x=4,8,12)$ reinforced with Saffil short fibers were prepared by the pressure-infiltration method. Stress-relaxation tests performed at room temperature helped us to identify thermally activated processes that occurred in the deformed matrix. The following conclusions from this study can be drawn:

- Components of the matrix stress were estimated.

- While the dislocation density in the $\mathrm{Mg}$ and $\mathrm{Mg} 4 \mathrm{Li}$ composites increased with strain, in the Mg12Li composite, the dislocation density decreased due to recovery.

- All values of the activation volume vs. effective stress dependence followed one "master curve" independent of the matrix alloy.

- The main thermally activated process in the hcp ( $\mathrm{Mg}, \mathrm{Mg} 4 \mathrm{Li})$ composites was very probably the dislocation motion in noncompact planes.

- The significant stress decrease during stress-relaxation tests in the Mg12Li composite was observed as a consequence of the massive recovery process. It was a very probable reason for the low value of the internal stress in the bcc matrix.

- The higher stress in the $\alpha$ phase and better ductility of the $\beta$ phase represent very good issues for many structural applications of the $(\alpha+\beta)$ alloys.

Author Contributions: Z.T. and P.L. conceived and designed the experiments; Z.D. carried out the mechanical tests and microstructure observation; Z.T., P.L., J.D. and Z.D. analyzed the data; Z.T. and P.L. wrote the paper. All authors have read and agreed to the published version of the manuscript.

Funding: The results were achieved with the use of support from the Ministry of Industry and Trade of the Czech Republic in the form of institutional funding.

Institutional Review Board Statement: Not applicable.

Informed Consent Statement: Not applicable. 
Data Availability Statement: Data sharing is not applied.

Acknowledgments: The authors acknowledge S. Kúdela from the Institute of Materials and Machine Mechanics, Slovak Academy of Sciences for the provision of the Mg-Li composites.

Conflicts of Interest: The authors declare no conflict of interest.

\section{References}

1. Feltham, P. Stress Relaxation in Magnesium at Low Temperatures. Phys. Status Sol. 1963, 3, 1340-1346. [CrossRef]

2. Sargent, G.A. Stress relaxation and thermal activation in niobium. Acta Met. 1965, 13, 663-671. [CrossRef]

3. Dotsentko, V.I. Stress Relaxation in Crystals. Phys. Status Sol. (B) 1979, 93, 11-43. [CrossRef]

4. Kubin, L.P. Description de la préplasticité par la théorie des phénomènes thermiquement activés. Philos. Mag. 1974, 30, 705-718. [CrossRef]

5. Caillard, D.; Martin, J.-L. Thermally Activated Mechanisms in Crystal Plasticity; Pergamon Materials Series; Elsevier: Oxford, UK, 2003; Volume 8.

6. Hariharan, K.; Jain, J. Stress relaxation test: Issues in modelling and interpretation. Manuf. Lett. 2020, 26, 64-68. [CrossRef]

7. Lo Picolo, B.; Spätig, P.; Kruml, T.; Martin, J.-L.; Bonneville, J. Characterising thermally activated dislocation mechanisms. Mater. Sci. Eng. A 2001, 309-310, 251-255. [CrossRef]

8. Bonadé, R.; Spätig, P. The evolution of the mobile dislocation density during successive stress relaxation transients. Mater. Sci. Eng. A 2008, 483-484, 203-206. [CrossRef]

9. Wu, R.Z.; Qu, Z.K.; Zhang, M.L. Reviews on the influences of alloying elements on the microstructure and mechanical properties of Mg-Li base alloys. Rev. Adv. Mater. Sci. 2010, 24, 35-43.

10. Zhou, Y.; Chen, Z.; Ji, J.; Sun, Z. Effects of second phases on deformation behavior and dynamic recrystallization of as-cast Mg-4.3Li-4.1Zn-1.4Y alloy during hot compression. J. Alloys Compd. 2019, 770, 540-548. [CrossRef]

11. Trojanová, Z.; Drozd, Z.; Lukáč, P.; Chmelík, P. Deformation behaviour of Mg-Li alloys at elevated temperatures. Mater. Sci. Eng. A Struct. 2005, 410-411, 148-151. [CrossRef]

12. Król, M.; Snopiński, P.; Pagáč, M.; Hajnyš, J.; Petrů, J. Hot Deformation Treatment of Grain-Modified Mg-Li Alloy. Materials 2020, 13, 4557. [CrossRef]

13. Kúdela, S. Magnesium-lithium matrix composites. An overview. Int. J. Mater. Prod. Technol. 2003, 18, 91-115. [CrossRef]

14. Sun, Y.H.; Wang, R.C.; Peng, C.Q.; Feng, Y.; Yang, M. Recent Progress in Mg-Li matrix composites. Trans. Nonferrous Met. Soc. China 2019, 29, 1-14. [CrossRef]

15. Trojanová, Z.; Drozd, Z.; Kúdela, S.; Száraz, Z.; Lukáč, P. Strengthening in Mg-Li matrix composites. Compos. Sci. Technol. 2007, 67, 1965-1973. [CrossRef]

16. Clyne, T.W.; Whithers, P.J. An Introduction to Metal Matrix Composites; Cambridge University Press: Cambridge, UK, 1993.

17. Aikin, R.M., Jr.; Christodoulou, L. The Role of Equiaxed Particles on the Yield Stress of Composites. Scr. Met. Mater. 1991, 25, 9-14. [CrossRef]

18. Casati, R.; Vedani, M. Metal matrix composites reinforced by nano particles-A review. Metal 2014, 4, 65-83. [CrossRef]

19. Li, J.M.C. Dislocation Dynamics in Deformation and Recovery. Can. J. Appl. Phys. 1967, 45, 493-509. [CrossRef]

20. De Batist, R.; Callens, A. On the analysis of stress relaxation experiments. Phys. Status Sol. (A) 1974, 21, 591-595. [CrossRef]

21. Kocks, U.F.; Argon, A.S.; Ashby, M.F. Thermodynamics and Kinetics of Slip, Prog. Mater. Sci. 19; Pergamon Press: Oxford, UK; Edingurg, UK; New York, NY, USA; Toronto, ON, Canada, 1975.

22. Barnett, M.R. Twinning and the ductility of magnesium alloys part I: Tension twins. Mater. Sci. Eng. A 2007, 464, 1-7. [CrossRef]

23. Barnett, M.R. Twinning and the ductility of magnesium alloys part II. "contraction" twins. Mater. Sci. Eng. A 2007, 464, 8-16. [CrossRef]

24. Taylor, G.I. The mechanisms of plastic deformation of crystals. Part I.-Theoretical. Proc. R. Soc. Lond. 1934, 145, $362-387$.

25. Lavrentev, F.F.; Pokhil, Y.A. Relation of dislocation density in different slip systems to work-hardening parameters for magnesium crystals. Mater. Sci. Eng. 1975, 18, 261-270. [CrossRef]

26. Cáceres, C.H.; Lukáč, P. Strain hardening behaviour and the Taylor factor of pure magnesium. Philos. Mag. 2008, 88, 977-989. [CrossRef]

27. Arsenault, R.J.; Shi, N. Dislocation generation due to differences between the coefficients of thermal expansion. Mater. Sci. Eng. 1986, 81, 175-187. [CrossRef]

28. Ashby, M.F. The deformation of plastically non-homogeneous materials. Philos. Mag. 1970, 21, 399-424. [CrossRef]

29. Trojanová, Z.; Lukáč, P.; Dlouhý, A. Hardening and softening in Zr-Sn polycrystals. Mater. Sci. Eng. A 1993, 164, $246-251$. [CrossRef]

30. Trojanová, Z.; Drozd, Z.; Halmešová, K.; Džugan, J.; Škraban, T.; Minárik, P.; Németh, G.; Lukáč, P. Strain Hardening in an AZ31 Alloy Submitted to Rotary Swaging. Materials 2021, 14, 157. [CrossRef]

31. Trojanová, Z.; Máthis, K.; Lukáč, P.; Németh, G.; Chmelík, F. Internal stress and thermally activated dislocation motion in an AZ63 magnesium alloy. Mater. Chem. Phys. 2011, 130, 1146-1150. [CrossRef]

32. Couret, A.; Caillard, D. An in situ study of prismatic glide in magnesium-I. The rate controlling mechanism. Acta Met. 1985, 33, 1447-1454. [CrossRef] 
33. Couret, A.; Caillard, D. An in situ study of prismatic glide in magnesium-II. Microscopic activation parameters. Acta Met. 1985, 33, 1455-1462. [CrossRef]

34. Trojanová, Z.; Száraz, Z.; Lukáč, P.; Drozd, Z.; Džugan, J. Strengthening and Thermally Activated Processes in an AX61/Saffil Metal Matrix Composite. Crystals 2020, 10, 466. [CrossRef]

35. Amadieh, A.; Mitchell, J.; Dorn, J.E. Lithium alloying and dislocation mechanisms for prismatic slip in magnesium. Trans. Aime $1965,233,1130$.

36. Máthis, K.; Nyilas, K.; Axt, A.; Dragomir-Cernatescu, I.; Ungár, T.; Lukáč, P. The evolution of non-basal dislocations as a function of deformation temperature in pure magnesium determined by X-ray diffraction. Acta Mater. 2004, 52, 2889-2894. [CrossRef]

37. Geng, J.; Nie, J.F. Unloading yield effect in a twin-roll-cast Mg-3Al-1Zn alloy. Scripta Mater. 2015, 100, 78-81. [CrossRef]

38. Trojanová, Z.; Lukáč, P.; Kainer, K.U.; Gartnerová, V. Dynamic strain ageing in selected magnesium alloys containing rare earth elements. Adv. Eng. Mater. 2005, 7, 1027-1032. [CrossRef]

39. Lubenets, S.V.; Startsev, V.I.; Fomenko, L.S. Strain ageing in Indium based alloys. Czech. J. Phys. B 1986, 36, 493-497. [CrossRef]

40. Balík, J.; Lukáč, P. On the kinetics of dynamic strain ageing. Kov. Mater. 1998, 36, 3-9.

41. Dlouhý, A.; Lukáč, P.; Trojanová, Z. Stress relaxations. Kov. Mater. 1984, 26, 688-694.

42. Taylor, G. Thermally activated deformation of bcc metals and alloys. Prog. Mater. Sci. 1992, 36, 29-61. [CrossRef]

43. Siedersleben, M.E.; Taylor, G. Slip systems in b.c.c. Li-Mg alloys. Philos. Mag. A 1989, 60, 631. [CrossRef]

44. Saka, H.; Taylor, G. Thermal-activation parameters for asymmetric $\{211\}$ slip in Li-Mg alloy crystals. Philos. Mag. A 1982, 45 , 973-982. [CrossRef]

45. Firth, L.D.; Nowaira, H.N.A.; Scott, W. Lattice parameters of lithium-magnesium and lithium-silver alloys. J. Phys. F Met. Phys. 1974, 4, L200. [CrossRef]

46. Čadek, J. Creep in Metallic Materials; Academia: Prague, Czech Republic, 1988.

47. Landau, A.I.; Dotsentko, V.D. Power-like dependence of the effective dislocation velocity on load resulting from the stochastic character of motion through a random array of point obstacles. Phys. Stat. Sol. (A) 1976, 37, 709-718. [CrossRef] 